US Congress acts on fears of nuclear plane plutonium disaster

\section{Washington \& Tokyo}

FEAR of a major nuclear disaster has driven a US Senate panel to take the unusual step of sending back to President Ronald Reagan for renegotiation the US-Japan nuclear agreement signed in November. The pact calls for plutonium to be flown from Europe to Japan by the polar route, raising fears that an accident could contaminate large areas of Alaska with deadly plutonium. Renegotiation will not be easy: a separate amendment to the budget bill requires the safety of plutonium storage casks to be tested in a plane crash before any flights are authorized.

Japan wants the plutonium, produced as a by-product in its light-water reactors, to use as a nuclear fuel. But to do so requires considerable international cooperation. First, Japan must send its spent fuel to France or the United Kingdom for the plutonium to be extracted and purified. Japan has only a tiny reprocessing plant of its own. And, second, Japan must obtain US consent because the fuel was sold to Japan under stringent US nuclear non-proliferation regulations.

The biggest problem is how to return the plutonium from Europe. Only $15 \mathrm{lb}$ is needed for a nuclear bomb so security has to be strict. An earlier attempt to send plutonium by sea from France turned out to be enormously expensive when, after two years of delay, an escort of two warships and continuous satellite surveillance had to be provided to satisfy the United States. The new US-Japan agreement would provide a cheaper route. Plutonium would be shipped by air, probably by the polar route via Anchorage (see Nature 330, 102; 1987). About one flight every two weeks, each carrying 500 lb of plutonium, would be required.

To avoid risk, the agreement specifies that the plutonium storage casks must be crash-proof. But, as Senator Alan Cranston, a member of the Senate Foreign Relations Committee which voted down the agreement put it, "the crashproof cask is not yet invented".

According to reports gathered by the Nuclear Control Institute, a Washingtonbased non-partisan policy institute, casks developed in the United States in cooperation with Japan, and in France, have failed miserably when slammed into a hard target at 250 knots. And as it is far from clear that the effects of a plane crash can easily be simulated, Congress has now specified that casks must be subjected to a real crash test unless an outside panel of experts agrees that a laboratory test of a worst-case accident is feasible.

At $\$ 25$ million, the crash of an old
Boeing 747 , full of test equipment, will not come cheaply. But supporters of the amendment say that it is a small price to pay for the security of knowing that a crash would not scatter plutonium over Alaska. If things really went wrong, cleaning up after a crash would be prohibitively expensive. When a military plane carrying nuclear warheads went down at Palomares, Spain, in 1966 , more than $\$ 500$ million was spent on removing plutoniumcontaminated soil. A second accident at Thule, Greenland, in 1968 cost $\$ 300$ million and required the removal of $150 \mathrm{mil}$ - lion gallons of snow, ice and water.

Rejection of the agreement by the Senate committee has already received backing in a similar move by the House of Representatives Foreign Affairs Committee. Both argue that the agreement does not meet the terms of the Nuclear NonProliferation Act. President Reagan is now faced with some difficult choices. He has to decide whether to renegotiate the agreement, exempt it from the nonproliferation act and send it back to Congress to see if he can win majority support in both Houses, or insist on it becoming law and risk a fight with Congress. The level of opposition now apparent in Congress suggests that he will take either of the latter two steps at his peril. Alun Anderson \& David Swinbanks

\title{
Enrolment mix raises ethnic issue at Berkeley, California
}

\section{Berkeley}

AsIAn-AMERICAN groups are in dispute with the University of California (UC) at Berkeley over admission policies which they claim discriminate against AsianAmerican applicants. That charge may seem implausible - Asian-Americans already take 40 per cent of undergraduate places in engineering and chemistry, and 28 per cent of total freshman class places. But Asian-Americans argue that if the admission process were unbiased, their admission rates would be higher still.

The remarkable academic performance of Asian-Americans is not restricted to Berkeley. Overall, Asian-Americans make up just 2 per cent of the US population. But at top universities they are consistently 'over-represented', taking 16 per cent of freshman places at Stanford, 14 per cent at Harvard and 20 per cent at the Massachussetts Institute of Technology.

The question of discrimination has also been raised elsewhere in California, but nowhere has the problem attracted so much attention as at Berkeley. Figures show that the overall admission rates (percentage of applicants admitted) are slightly lower for Asian-Americans than for comparable white applicants.

At Berkeley last year, nearly 2,000 undergraduate applicants with top examination scores had to be turned away. Half of Berkeley's entrants are chosen on test scores alone and most of the remainder on evaluation of mathematics and foreign language background, English proficiency and a written essay. Under-represented minorities (blacks, Hispanics and American-Indians), recruited athletes, handicapped and rural students, are guaranteed admission if they meet basic UC eligibility requirements.

Asian-Americans claim that the way credit is given for foreign languages lowers their chances of admission. Students who have grown up speaking an Asian language cannot use that skill to their advantage because the US standardized achievement tests do not include tests in Asian languages. The university counters by arguing that the difference in admission rates can be accounted for by the underrepresentation of Asians among the recruited athletes and rural students guaranteed admission. But the university now intends to give full language credit to students who have immigrated from nonEnglish speaking countries.

The graduate admissions process may be more difficult to evaluate, says Eugene Cota-Robles, assistant UC vice president for academic planning. Asians comprise 8 per cent of UC graduate students, and are clustered in the professional schools and science and engineering departments. Cota-Robles says that some apparent discrepancies between admission rates for Asian and white applicants to UC graduate programmes have actually resulted from a skewing of Asian applicants toward highly competitive programmes such as medicine, law, business and engineering.

Nevertheless, further examination of graduate admissions on the Berkeley campus has shown that Asian admission rates lag behind white rates by 16 percentage points in some graduate departments. The reasons for the discrepancies are as yet unclear, but the dean of the graduate division has launched an inquiry into admissions policy in those departments.

Berkeley chancellor Ira Michael Heyman has also set up a campus task force, made up of students, staff, faculty and members of the Asian community, to examine all of the opportunities and disadvantages faced by Asian students at Berkeley.
Marcia Barinaga 